DOI 10.37882/2500-3682.2021.08.03

\title{
ПРОБЛЕМАТИКА ВОПРОСА МУЛЬТИКУЛЬТУРАЛИЗМА И СОЦИАЛЬНО-ПСИХОЛОГИЧЕСКОЙ ТОЛЕРАНТНОСТИ В УСЛОВИЯХ ГЛОБАЛИЗАЦИИ И ВСЕОБЩЕЙ ИНТЕГРАЦИИ
}

\section{PROBLEMS OF THE ISSUE \\ OF MULTICULTURALISM \\ AND SOCIO-PSYCHOLOGICAL TOLERANCE IN THE CONTEXT \\ OF GLOBALIZATION AND UNIVERSAL INTEGRATION}

N. Volkova

Summary: This article analyzes the state of research and development of theoretical and methodological foundations for the study of multiculturalism in the works of foreign scientists; the connection of this phenomenon with the category of national tolerance in the context of globalization and universal integration is traced, and it is also shown that the concept of multiculturalism is much broader than tolerance, since it includes not only tolerance, but also active support of group differences and the transformation of social life for the full inclusion of members of various ethnic groups.

Keywords: multiculturalism, tolerance, socio-cultural and sociopsychological variability, multicultural identity, polyethnicity, multiculturalism.

\author{
Волкова Наталья Александровна \\ аспирант, Московский государственный университет \\ имени М.В. Ломоносова \\ Volkovanat189@gmail.com
}

Аннотация: В данной статье проводится анализ состояния изучения и разработки теоретико-методологических основ исследования мультикультурализма в трудах зарубежных ученых; прослеживается связь этого феномена с категорией национальной толерантности в условиях глобализации и всеобщей интеграции, а также показано, что понятие мультикультурализма значительно шире толерантности, поскольку включает не только терпимость, а также активную поддержку групповых различий и трансформацию общественной жизни для полноценной инклюзии членов различных этногрупп.

Ключевые слова: мультикультурализм, толерантность, социо-культурная и социо-психологическая вариативность, мультикультурная идентичность, полиэтничность, поликультурность.
A ктуальность предложенной проблематики определяется необходимостью фундаментального анализа трансформаций национальной психологии народов в условиях быстрого роста социо-культурной и социо-психологической вариативности. Разработка новейших концептуальных подходов к осмыслению широкого спектра вопросов, связанных с национальнокультурной разнородностью социума, требует глубинного исследования содержательной сущности феномена мультикультурализма и его связей с сопредельными категориями, в частности - с понятием национальной толерантности.

\section{Анализ последних исследований}

Методология мультикультурализма является новой для отечественной психологической науки, чем, собственно, и можно объяснить отсутствие фундаментальных исследований в этом направлении. В контексте предложенной проблематики стоит вспомнить труды таких ученых как: В. Антонова, Ф. Аткинсона, Дж. Бэнкса, Л. Дерман-Спаркса, М. Дженкинса, В. Кимлики, Ч. Кукатиса, Дж. Льюиса, В. Малахова, Ш. Рамона, Д. Сакса,
В. Тишкова, В. Уоткинса, Б. Уинг, В. Холла, Т. Щедрина и др. Ценным также являются исследования и разработка механизмов национальной толерантности и антидискриминационной практики (А. Асмолов, Ю. Арутюнян, Л. Дробижева, В. Крысько, Н. Лебедева, А. Реан, Г. Солдатова, Т. Стефаненко, В. Тишков, П. Шихирев, А. Шлягина и др.). В научной литературе мультикультурализм, как целостный психологический феномен подробно не изучен, на фоне попыток операционировать это понятие в контексте психологической парадигмы. Кроме того, недостаточно освещена проблема соотношения мультикультурализма и национальной толерантности в пределах психологических концепций.

Цель статьи - проанализировать состояние изучения и разработки теоретико-методологических основ исследования мультикультурализма в трудах зарубежных ученых, а также проследить связь этого феномена с категорией национальной толерантности в условиях глобализации и всеобщей интеграции. 


\section{Изложение основного материала и обоснование} полученных результатов исследования

Феномен мультикультурализма не является новым для психологической науки, однако эмпирическое исследование предложенной проблематики началось лишь с 1990-х годов. Изучение понятия «мультикультурная идентичность», как указывает, например, А.С. Гордеев [3] является ценным, особенно в контексте социальной и индивидуальной психологии, поскольку вопрос того, как у индивидов развивается чувство сообщества, национальной, культурной, этнической и расовой групповой принадлежности становится чрезвычайно актуальным в условиях культурного плюрализма и интеграции. Именно социально-психологические факторы, которые влияют на развитие мультикультурной идентичности, обеспечивают психологов тем инструментарием, который делает исследование индивидуальных вариаций динамики Я-концепции.

В широком смысле мультикультурными есть личности, которые продолжительный период проживали в разных странах, воспитывались в поликультурной среде (кроме господствующей культуры, в обществе присутствовали культуры национальных меньшинств), активно были включены в межкультурные отношения и тому подобное. С точки зрения психологии, не существует единой согласованной трактовки мультикультурализма. Как правило, мультикультурными считаются индивиды, самоназвание которых (Я - мультикультурная личность) или групповая самокатегоризации (Я - русский) отражает их культурный плюрализм.

В узком смысле мультикультурализм целесообразно интерпретировать как индивидуальный опыт личности, находящейся под влиянием и принимающей особенности двух или более культур. В таком случае мультикультурная идентичность может пониматься как осознание личностью своей принадлежности и наличие внутренней связи с определенными культурами. Важно понимание того, что мультикультурная идентичность является лишь одним из компонентов комплексного и многомерного феномена мультикультурализма. Другими словами, результатом воздействия нескольких культур на индивида и ознакомления его с их особенностями, как считает В.Н. Блохин [1], является формирование мультикультурной личности, и только глубинное осознание своей принадлежности к нескольким культурным системам дает основания утверждать о наличии мультикультурной идентичности у такой личности.

Мультикультурный опыт расширяет когнитивный инструментарий индивида и дает ему возможность усвоить соответствующие когнитивные средства для решения проблем в определенной культурной среде. То есть, личности, которые находятся под влиянием нескольких различных культур, приобретают и используют в даль- нейших поведенческих стратегиях знания, связанные с соответствующими культурными кодами, для управления своим поведением в рамках конкретных культурных систем. Мультикультурный опыт также поощряет контекстуализация культурного знания. Индивиды с расширенным мультикультурным опытом осознают культурную специфику единиц знания в их когнитивном инструментарии и дифференцированную связанность различных единиц знания с различными культурными традициями (например, для американо-индийской бикультурной личности понятие человеческих прав является более связанным с американскими традиции, а понятие дхармы с индийской). Благодаря такому контекстуализированому знанию - подчеркивает А.С. Гордеев [3] - мультикультурные личности часто проявляют высокий уровень поведенческой реакции на определенные ситуативные сигналы, что свидетельствует о релевантности различных культурных сценариев.

Согласно точки зрения П. Адлера [7], стоит говорить о существовании нового типа мультикультурной личности, появляющейся в мультикультурной реальности, это личность, не укорененная в определенной культуре, и способная изменять свою идентичность и свойства с целью эффективного существования и функционирования между культурами.

Со своей стороны Дж. Вате [12] выдвигает гипотезу о том, что человек эпохи постмодерна в-принципе не будет одержимым проблемой идентичности перестав воспринимать себя как незыблимое единство.

В плоскости социологии мультикультурализм понимается как особенная форма интегративной идеологии, с помощью которой полиэтнические, поликультурные национальные сообщества реализуют стратегии социального согласия и стабильности на принципах равноправного сосуществования разных форм культурной жизни.

В работах современных исследователей мультикультурализм рассматриваются как система убеждений и поведенческих стратегий, которая признает и уважает наличие всех разнообразных групп в определенном обществе, допускает и ценит их социокультурные различия, а также поощряет их сотрудничество в контексте культурной инклюзии.

Б. Берри [8] интерпретирует мультикультурализм как ориентацию, которая предусматривает поддержку культурной идентичности и особенностей всех этнокультурных групп, с одной стороны, и взаимодействие и участие всех этногрупп в жизни определенного общества, с другой стороны. Ученый считает, что именно такая трактовка этого феномена позволит исследовать психологические основы социальных политик различных государств по мультикультурализму. 
О.С. Головачева [4] различает определенные модели мультикультурализма, а именно: «мягкую», «жесткую», «доминантную» и «эгалитарную». «Мягкая» модель мультикультурализма предполагает, что интеграция индивида в мультикультурную среду происходит добровольно и только по желанию, не создаются особые условия культурного сближения. «Жесткая» модель приводит организацию определенных условиях не только для полноценного привлечения инокультурных индивидов в общественную жизнь, но и для сохранения их культурной идентичности. Особенности «доминантной» и «эгалитарной» моделей заключаются в том, что в контексте первой культура национального большинства является господствующей относительно культур национальных меньшинств, В то время как вторая предусматривает устранение любых барьеров социального, экономического, политического и т.д. участия представителей различных культур в жизни определенной национальной общности.

Феномен мультикультурализма неоднозначно воспринимают представители национального большинства и меньшинства, поскольку первые считают его влияние угрожающим в контексте формирования национальной идентичности, в то время как вторые - благоприятным фактором. Члены национального большинства воспринимают этнонациональные меньшинства и их стремление к сохранению своей культуры как угрозу господствующей культурной среды и групповой идентичности. Согласно социальным психологическим теориям, которые акцентируют внимание на роли группового статуса и интересов в динамике развития межгрупповых отношений, очевидно, что группы менее одобрительно воспринимают мультикультурализм, если он определенным образом противоречит их материальным и духовным интересам.

Таким образом, мультикультурализм позитивно воспринимают представители национальных меньшинств, чем национальное большинство, что, в свою очередь, активно пропагандирует стратегию ассимиляции культурных сообществ. Поддержка и признание культурных отличий в пределах определенной национальной общности может оказаться демотивирующим фактором для представителей национального большинства, поскольку они рассматривают подобную политику как таковую, что грозит их групповому статусу и идентичности.

По вопросу соотношения мультикультурализма с феноменом национальной толерантности стоит отметить, что именно формирование толерантности, безусловно, является первоосновой положительных взаимосвязей и отношений между различными этнонациональными сообществами. Однако национальная толерантность является направляющим вектором гармоничного сосуществования мультинационального общества, ведь оно предполагает прежде всего не то, что все его пред- ставители похожи друг на друга, а то, что они являются толерантными к «другим». Феномен мультикультурализма значительно шире - подчеркивает П.А. Тихонова [6] - чем толерантность, поскольку он включает активную поддержку групповых различий и трансформацию сфер общественной жизни для полноценного включения членов национальных меньшинств.

Сторонники мультикультурализма утверждают, что только толерантности недостаточно для равноценного и равноправного функционирования вариативных национальностей в рамках общества и именно мультикультурализм предполагает активную поддержку культурных отличий. Мультикультурализм обусловливает не игнорирование или устранение различий, а их признание и оценку. Когда речь идет о толерантности относительно определенных этнонациональных сообществ, то, как правило, она рассматривается как желание или стремление национального большинства смириться с культурными особенностями и различиями национальных меньшинств. В таком случае конечным результатом толерантности для представителей национального меньшинства является толерантность их особенностей, а не утверждение или признание.

Однако следует отметить, что толерантность не стоит отождествлять с релятивизмом или безусловным принятием различий «другого». Ученые отмечают, что степень толерантности зависит от таких факторов, как «кого», «что» и «когда» респондент терпит. Так, в частности, исследования [5 и др.] показали, что взрослые проявляли высокую степень толерантности по отношению убеждений и поступков, которые базировались на отличной информации, чем на отличных моральных убеждениях. Даже больше, принятие того, что люди имеют другие взгляды и убеждения, не обязательно предполагает, что индивид будет толерантным к общественному выражению подобных взглядов или поступков.

В плоскости предложенной проблематики стоит, по нашему мнению, рассмотреть также вопрос национальной идентичности и национальной идентификации. Изучение внутригрупповой идентификации является важным для понимания того, как национальное большинство реагирует на культурное и религиозное многообразие, что характерно для определенного сообщества. Общая концепция заключается в том, что чем выше степень идентификации представителей национального большинства, тем более вероятным является тот факт, что они будут защищать групповые интересы и групповой статус, пропагандируя, например, стратегию ассимиляции.

В работах зарубежных исследователей [10; 11 и др.] предлагаются модели объяснения роли внутригрупповой идентификации сквозь призму внешнегрупповой угрозы идентичности группы и поддержки мультикуль- 
турализма считая, что высшей степенью групповой идентификации является более глубокое восприятие угроз через проявление соответствующей реакции пропаганды мультикультурных психологических характеристик.

Иная форма «реакция коллективной идентичности» основывается на мысли, то что понимание коллективный опасности приводит к ситуации, когда происходит большая идентификация индивидов со своей группой, что вызывает негативные внешнегрупповые аттитюды. что индивиды больше определяют себе с собственной командой, то что, непосредственно, приводит во следствии ко отрицательным внешнегрупповым аттитюдам. Но при этом общество обладает шансами справиться с внешнегрупповыми угрозами, адаптируя стратегии, которые направлены на увеличение внутригрупповой идентификации.

Форма модели «посредника коллективной идентичности» предусматривает, тот аспект, что внутригрупповая идентификация вступает во взаимодействие с внешнегрупповой опасностью в целях одобрения идеологии мультикультурализма и закрепления прав за национальными меньшинствами.

Согласно с концепцией межкультурного взаимодействия канадского ученого Дж. Бери [8] аккультурационные стратегии формируются двумя компонентами: социокультурными установками и реальной моделью поведения индивида в определенных условиях, редко совпадающих. Объяснение состоит в том, что усвоение формализованных моделей поведения зачастую расходятся с мотивацией личности в процессе принятия определенного поведенческого решения и как результата социальных ограничений поведения (норм, возможностей и т.д.). Происходит ориентация людей на собственную группу (с целю сберечь свое культурное наследие и идентичность) и на иные группы (контактирование с сообществом в целом и участие в жизни сообщества, в котором сосуществуют представители прочих этногрупп).

Присутствие заинтересованности в сохранении собственной культурной идентичности и формирование партнерских отношений с членами прочих этногрупп говорит о существовании аккультурационной стратеги интеграции.

Также, в конечном итоге, маргинализация обозначает низкую (либо целиком недостаточны) интерес в обеспечении сохранности цивилизованной идентичности, а также взаимодействия с иными культурными цивилизациями, факторами чего зачастую бывают исключения либо ограничение в правах [2].

Мультикультурализм сопряжен со стратегией аккультурационной интеграции, так как непосредственно предусматривает тесную связь представителей разных национальных цивилизаций при поддержке культурной идентичности, то что, непосредственно, возможно только лишь в ситуации мультикультурной среды. Но имеется суждение, то что мультикультурализм обозначает в первую очередь в целом помощь множества культур в обществе в отсутствии их особенной связи воздействия либо партнерства. В этом случае происходит корреляция мультикультурализма с сепарацией, таким образом имеется опасность акцентуации культурных отличий, а также усиление формы мышления по типу «Мы-Они». Другие ученые считают [9 и др.], что мультикультурализм не является чистой интеграцией, поскольку воспринимается как временное средство на пути к ассимиляции. Такая точка зрения, как правило, характерна для представителей национальных меньшинств, которые убеждены, что взаимодействие с доминантной группой приведет к потере их культурной идентичности. В современных условиях глобализации и сотрудничества национальных сообществ, мультикультурализм является основой интеграционных стратегий, поскольку предполагает существование всеохватывающих рамок общих ценностей, которые функционируют как опора в мультиэтническом государстве, рамок, гибких и чувствительных к разнообразным культура, которые образуют нацию.

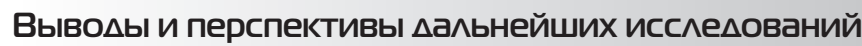

Таким образом, феномен мультикультурализма в соответствии с зарубежной психологической теорией рассматривается как система убеждений и поведенческих стратегий, которая признает и уважает наличие всех этнокультурных групп в определенном обществе, терпит их социокультурные и социо-психологические различия, а также поощряет их взаимодействие и сотрудничество. Анализ научных работ по данной проблематике позволил констатировать, что основательное изучение проблемы мультикультурализма предусматривает рассмотрение этого понятия в контексте исследования таких психологических категорий, как национальная идентификация и идентичность, национальное большинство и меньшинство, внутригрупповая идентификация и внешнегрупповая угроза, аккультурационные стратегии и тому подобное. Соотношение феноменов мультикультурализма и национальной толерантности показало, что понятие мультикультурализма значительно шире толерантности, поскольку включает не только терпимость, а также активную поддержку групповых различий и трансформацию общественной жизни для полноценной инклюзии членов различных этногрупп.

Перспективами дальнейших исследований может служить попытка теоретико-методологического и эмпирического изучения формирования национальной толерантности в условиях мультикультурных обществ. 


\section{ЛИТЕРАТУРА}

1. Блохин В.Н. Феномен мультикультурализма // Диалог культур в глобализирующемся мире: Материалы III Всероссийской научно-практической конференции (с международным участием) / Под ред. В.Э. Манаповой. - Махачкала: АЛЕФ, 2020. 182 с.

2. Бондаренко Ю.В. Идея мультикультурализма в современном обществе // Актуальные проблемы государства и общества в области обеспечения прав и свобод человека и гражданина. № 1. 2020. С. 102-106.

3. Гордеев А.С. Мультикультурализм как модель эффективной межкультурной коммуникации // Студенческая наука - взгляд в будущее. 2020. С. $372-374$.

4. Головачева 0.С. Мультикультурализм как модель поликультурного общества мировых держав и его применение в современной России // Журнал научных публикаций аспирантов и докторантов, 2008. № 8. С. 93-96.

5. Негода Л.Л. Толерантность и интолерантность в контексте социального измерения // Актуальные эколого-политологические аспекты современности. 2020. С. 76-79.

6. Тихонова П.А. Упадок культуры западного общества. Парадокс политики мультикультурализма // Достижения науки и образования 17 (71) (2020). C. 53-55.

7. Adler P. Beyond cultural identity: reflections on cultural and multicultural man / P. Adler//Cultural learning: Concepts, application and research/ed. R.W. Bristian. Honolulu, 1997. P. 24-41.

8. Berry J.W. Cross-cultural psychology / John W. Berry, Ype H. Poortinga, Marshall H. Segall, Pierre R. Dasen. - Camridge University Press, 2002.588 p.

9. Crisp R.J. Multiple social categorization [In M.P. Zanna (Ed.)] / R.J. Crisp \&M. Hewstone // Advances in Experimental Social Psychology. - Vol. 39. - Orlando, FL: Academic Press, 2007. P. 163-254.

10. Gurin P. Context identity and intergroup relations [In D. Prentice \& D. Miller (Eds.)] / P. Gurin, T. Peng, G. Lopez, \& B. R. Nagda // Cultural divides: The social psychology of intergroup contact. - New York: Sage, 1999. P. 133-170.

11. Nguyen A.-M. D. Biculturalism unpacked: Components, individual differences, measurement, and outcomes / A.-M. D. Nguyen \& V. Benet-Martinez // Social and Personality Psychology Compass. 2007. № 1. P. 101-114.

12. Vattimo G. Rozdiely, konflikty, kultúrny minimalizmus / G. Vattimo // Aspekt. 1997. № 2. C. 223.

\footnotetext{
(с) Волкова Наталья Александровна (Volkovanat189@gmail.com).

Журнал «Современная наука: актуальные проблемы теории и практики»
}

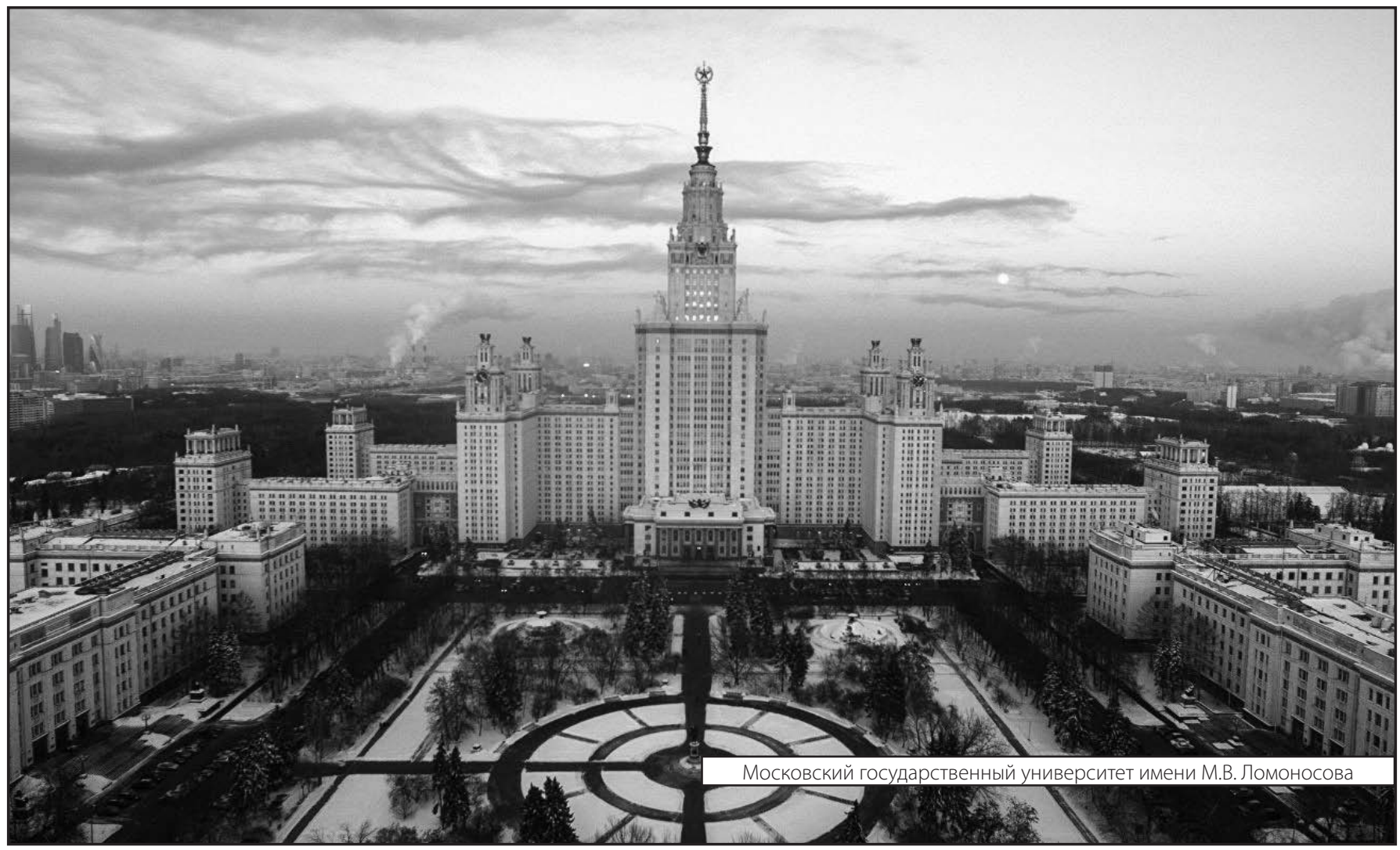

